\title{
Daily global fire radiative power fields estimation from one or two MODIS instruments
}

\author{
S. Remy ${ }^{1}$ and J. W. Kaiser ${ }^{2,3,1}$ \\ ${ }^{1}$ European Centre for Medium-Range Weather Forecasts, Reading, UK \\ ${ }^{2}$ King's College London, London, UK \\ ${ }^{3}$ Max-Planck-Institut für Chemie, Mainz, Germany \\ Correspondence to: S. Remy (samuel.remy@ecmwf.int)
}

Received: 22 April 2014 - Published in Atmos. Chem. Phys. Discuss.: 12 August 2014

Revised: 21 October 2014 - Accepted: 17 November 2014 - Published: 16 December 2014

\begin{abstract}
Fires are important emitters of aerosol and trace gases and as such need to be taken into account in any atmospheric composition modelling enterprise. One method to estimate these emissions is to convert fire radiative power (FRP) analysis into dry matter burnt and emissions of smoke constituents using land-cover-dependent conversion factors. Inventories like the Global Fire Assimilation System (GFAS) follow this approach by calculating daily global smoke emissions from FRP observed by the MODIS instruments onboard the Terra and Aqua satellites. Observations with different overpass times systematically sample fires at different stages in the strong diurnal fire cycle. For some time periods, observations are available from only one instrument, which leads to a bias in the observed average FRP.

We develop a method to correct this bias in daily FRP observations from any low Earth orbit (LEO) satellite, so that the budget of daily smoke emissions remains independent of the number of satellites from which FRP observations are taken into account. This ensures the possibility of running, for example, GFAS in case of failure of one of the MODIS instruments. It also enables the extension GFAS to 2000-2002 and the inclusion of FRP observations from upcoming satellite missions. The correction combines linear and non-linear regressions and uses an adaptive regionalization algorithm. It decreases the bias in daily average FRP from Terra and Aqua by more than $95 \%$, and RMSE by $75 \%$ for Aqua and $55 \%$ for Terra. The correction algorithm is applied to Terra observations from 25 February 2000 to 31 December 2002, when Aqua observations were not available. The database of fire emissions GFASv1.0 is extended correspondingly.
\end{abstract}

\section{Introduction}

\subsection{Importance of biomass burning emissions in atmospheric composition modelling}

Vegetation fires are a frequent occurrence in all vegetated environments. They are ignited naturally (i.e. by lightning) or by anthropogenic activity. They can be the cause of serious public health issues such as the extreme particulate matter (PM) concentrations recorded in Singapore at the end of June 2013, caused by fires in the neighbouring island of Suma$\operatorname{tra}^{1}$. Depending on the vegetation cover, fires emit various aerosols, reactive gases and greenhouse gases. More specifically, fires are a major source of black carbon in the atmosphere: they are responsible for around $40 \%$ of the emissions of carbon monoxide $(\mathrm{CO})$, a precursor gas for ozone $\left(\mathrm{O}_{3}\right)$. They are also an important source of nitrogen oxides $\left(\mathrm{NO}_{\mathrm{x}}\right)$. As such, biomass burning emissions play an important role in chemical composition and air quality forecasts.

Fires also affect the radiative balance of the atmosphere by emitting greenhouse gases such as carbon dioxide $\left(\mathrm{CO}_{2}\right)$ and methane $\left(\mathrm{CH}_{4}\right)$. They also release large quantities of aerosol particles such as black carbon (BC) and organic carbon (OC), which in turn impact the atmosphere through the aerosolradiation and aerosol-cloud interactions. Diehl et al. (2012) estimate the global $\mathrm{OC}$ emissions from biomass burning as $14-57 \mathrm{Tg} \mathrm{yr}^{-1}$, while $\mathrm{BC}$ ranges from 1.8 to $7 \mathrm{Tg} \mathrm{yr}^{-1}$. Bond et al. (2013) cite ranges of $2-11 \mathrm{Tg}(\mathrm{BC})$ and $18-77 \mathrm{Tg}$ (organic carbon) for the global annual estimates of emissions from open biomass burning. Out of 13 identified radiative

\footnotetext{
${ }^{1}$ See http://www.gmes-atmosphere.eu/news/singapore_smoke
} 
forcing agents (Bowman et al., 2009), 8 are impacted by fires. Therefore, taking into account the contribution of fires in the emissions of aerosols, reactive gases and greenhouses gases is a necessary step in any atmospheric composition modelling enterprise.

Fires occur mostly in locations where in situ observations are not available and are characterized by a large temporal and spatial variability; assessing their size and intensity requires the use of remote observations. Most fires are characterized by a strong diurnal cycle (e.g. Giglio, 2007; Roberts et al., 2009), often with a maximum in the early afternoon. Satellite observations of the currently active fires are the only source that can provide a global estimation of fire activity. Several systems that calculate the biomass burning emissions from satellite observations of burnt area or active fire areas have been developed over the recent years (van der Werf et al., 2006, 2010; Freitas et al., 2005; Reid et al., 2009; Sofiev et al., 2009; Kaiser et al., 2009, 2012).

The Moderate Resolution Imaging Spectroradiometer (MODIS) instrument observes thermal radiation around 3.9 and $11 \mu \mathrm{m}$ wavelengths. Thermal radiation includes signals not only from fires but also from volcanoes and gas flares that will need to be masked. From this source of information, NASA produces the MOD14 product (Justice et al. (2002) and Giglio, 2005), which contains a quantitative observation of fire radiative power (FRP). FRP represents the amount of power that is released by the fire into the atmosphere, in $\mathrm{W} \mathrm{m}^{-2}$. The Spinning Enhanced Visible and Infrared Imager (SEVIRI) onboard the Meteosat- 8 satellite also provides estimates of FRP using the middle infrared (MIR) radiance method (Wooster et al., 2003).

The European Union-funded project "Monitoring Atmospheric Composition and Climate-Interim Implementation" (MACC-II) provides global analysis and forecasts of atmospheric composition, alongside European air quality forecasts (Hollingsworth et al., 2008). In order to provide this forecasting system with accurate estimates of aerosol, reactive gases and greenhouse gas emissions from biomass burning, the Global Fire assimilation System (GFAS; Kaiser et al., 2009), based on satellite-based FRP observations, was developed. GFAS grids and averages FRP observations from the MODIS instrument onboard NASA's Terra and Aqua satellites. FRP observations from sensors onboard geostationary satellites such as Meteosat- 8 and GOES East and West are currently not used in GFAS, as their values are very different from MODIS. This gridded data from the two satellites are then merged to produce global daily averaged FRP fields with $0.5^{\circ}$ and $0.1^{\circ}$ resolutions. An analysis of daily averaged FRP is then built by assimilating this merged daily averaged FRP observation. The assimilation step consists of a simple Kalman filter used with a persistence model; its objective is to fill the observational gaps, caused mainly by cloudy conditions.

Heil et al. (2010) found strong correlations between FRP and the dry matter combustion rate of the Global Fire Emis- sion Database (GFED; van der Werf et al., 2010) v3.1. This allowed for the derivation of conversion factors for eight land cover classes that link GFAS FRP to GFED dry matter combustion rate, which allows for GFAS to provide a global analysis of dry matter burnt. Emission factors following Andreae and Merlet (2001) are then used to estimate the emissions of 41 species from the dry matter burnt estimate. As GFAS translates a daily averaged FRP into a daily average emission rate of species (Kaiser et al., 2012), it contains no information about the diurnal cycle of biomass burning emissions. Our aim here is to try to reproduce this daily average FRP and biomass burning emissions using one source of observations instead of two.

The MACC-II project also produced an 8-year reanalysis (Inness et al., 2013) of global atmospheric composition, using biomass burning emissions estimates from GFED and GFAS. The biomass burning emissions database was then extended from 1 January 2003 to the current day. Besides its everyday use in the MACC-II global atmospheric composition forecasts, this database is attracting a growing number of users worldwide.

\subsection{Satellite observations used in real-time emission calculation}

Only low Earth orbit (LEO) satellites provide full global observational coverage, and the MODIS instruments onboard NASA's polar-orbiting satellites Aqua and Terra are the only instruments for which fire products are currently provided in real time (Giglio et al., 2003, 2006). The FINN (Wiedinmyer et al., 2011) and FLAMBE emission inventories (Reid et al., 2009) use hotspot observations from MODIS. Other real-time inventories, e.g. GFAS, QFED (Darmenov and da Silva, 2013) and IS4FIRES (Sofiev et al., 2009), use the additional quantitative information of the FRP products from the MODIS satellites. Both observations are only available for clear-sky conditions, and show a decreasing accuracy as the viewing angle increases (Freeborn et al., 2011). The Terra overpass time is around 10:30 local solar time in its descending mode and 22:30 local solar time in its ascending mode. The Aqua overpass times are around 13:30 (01:30) local solar time in ascending (descending) mode.

The diurnal fire cycle is reflected in a significant bias in the FRP observations from the two MODIS instruments (Giglio, 2007; Roberts et al., 2009). This bias has a strong geographic dependency because the diurnal cycle of fire intensity depends on the land cover type: for example, peat fire intensity hardly varies between day and night, while savannah fires nearly extinguish at night. Accurate emission inventories need to combine as much information as possible. For example, GFAS currently merges observations from Aqua and Terra, weighted by the observed area product, which depends on the cloud cover. That means that the relative signal from both satellites in the final GFAS FRP analysis is varying from day to day. To summarize, the difference between 
Terra and Aqua FRP can be caused by the diurnal cycle of fires and by a change in cloudiness between their overpass times.

While running GFAS with FRP observations from only Aqua or Terra is technically feasible with the current configuration, the above shows that if we want to ensure that the daily averaged FRP and biomass burning emissions are coherent with the classical configuration (i.e. assimilating data from both satellites), a correction step is required. This also applies to other emission inventories that use MODIS observations with a temporal resolution of 1 day or more. Availability of only one MODIS instrument occurs in three situations: before the launch and start of product generation from Aqua (02/2000-12/2002); during short breaks in the real-time availability of either MODIS instrument; and, in the future, after the lifetime of whichever instrument fails first.

\subsection{Objectives of this work}

The objective of this work is to develop a method that can adequately correct the FRP products from LEO satellites such that daily averaged FRP, and thus biomass burning emission, estimates remain unbiased between time periods with all satellites available. The method will be derived for MODIS observations from the Terra and Aqua satellites, but it will also be applicable for VIIRS and Sentinel-3 observations. It will be used to extend the GFAS emission inventory back to 2000. It will also provide resilience of GFAS against failure of one of the MODIS instruments, and prepare for the ingestion of FRP products of NPP VIIRS and Sentinel-3 SLSTR in as soon as they become available in real time.

Ellicott et al. (2009) succeeded in using observations from Terra only to estimate monthly averaged FRE (Fire Radiative Energy), with only a small bias from using observations from Aqua and Terra. The system used in their work was rather different from GFAS, as it estimated a diurnal cycle based on geostationary satellites and did not include a data assimilation step to fill observational gaps. Our aim, however, is to reach the same results with daily averaged FRP and biomass burning emissions.

Section 2 describes the statistical methods used to correct the daily observations from Aqua or Terra; the results from these methods are shown in Sect. 3. Section 4 shows how the GFAS database was extended back to 2000 by using corrected observations from Terra only. Finally, Sect. 5 summarizes the results of this paper, and Sect. 6 offers some conclusions.

\section{Methods}

\subsection{Overall approach}

Since fires vary so much both spatially and temporally and the relative contribution of Aqua and Terra FRP observations to the final product varies from day to day, it is not realistic to aim to reproduce the local and temporal variability of fires as sampled by two sources of observations when running with only one source. Also, cloudiness changes and the diurnal cycle of fires introduce differences between Aqua and Terra. We will focus here on trying to compensate for the effect of the diurnal cycle on observed FRP. A statistical regression fit from a learning data set will be used, the quality of its output will be assessed using an independent verifying data set.

\subsection{Choice of variables}

GFAS assimilates merged FRP observations in a $24 \mathrm{~h}$ window to produce a best estimate of the daily average FRP, from which emissions of various gases and aerosols are derived. We will work on these daily FRP observations instead of FRP analysis from GFAS or directly on the emissions. As global observations from Aqua or Terra are collected within a $12 \mathrm{~h}$ span, it makes sense to use a longer period for our explanatory variable: a $24 \mathrm{~h}$ period is the best choice as it allows us to directly apply the correction to the merged observations that are assimilated in GFAS. For the same reason, it was preferred to scale daily observations of Terra (Aqua) toward merged FRP from both satellites instead of towards observations from the other satellite.

\subsection{Learning and verification data sets}

The learning data set is composed of daily averages of FRP from Aqua and Terra, averaged over a $0.5^{\circ}$ grid by the GFAS algorithm. It extends from 1 January 2003 to 31 December 2011. To prevent taking into account situations where Aqua and Terra observations are very different, for example because of a change in cloudiness, fires for which the ratio of Terra- or Aqua-GFAS over Full-GFAS was above the ninth decile of the whole data set for the considered day were not included in the data set. The effect of this exclusion was shown to increase the correlation coefficient between the data sets by up to $20 \%$, especially over Africa.

The diurnal cycle, and thus the physics underlying the statistical link between FRP observations from Aqua and Terra, depends on the land cover; therefore an application of a regression algorithm to global FRP needs to take this dependency into account. Also, fire typology varies a lot from region to region. Tropical regions dominated by large forests and savannah exhibit large seasonal fire activity that is longlasting and relatively regular. These regions contribute a lot to global FRP. Boreal regions with forests mostly composed of coniferous trees are, on the other hand, subject to fire events that are much more irregular in size and intensity. A few large events such as the Rim fire of August 2013 in California or the Quebec fires of June and July $2013^{2}$ that sent a plume crossing the Atlantic and affecting Europe can have a

\footnotetext{
${ }^{2}$ See http://www.copernicus-atmosphere.eu/news/canada smoke/ and http://www.wunderground.com/blog/JeffMasters/ canadas-2nd-largest-fire-on-record-spreading-smoke-to-europe
} 


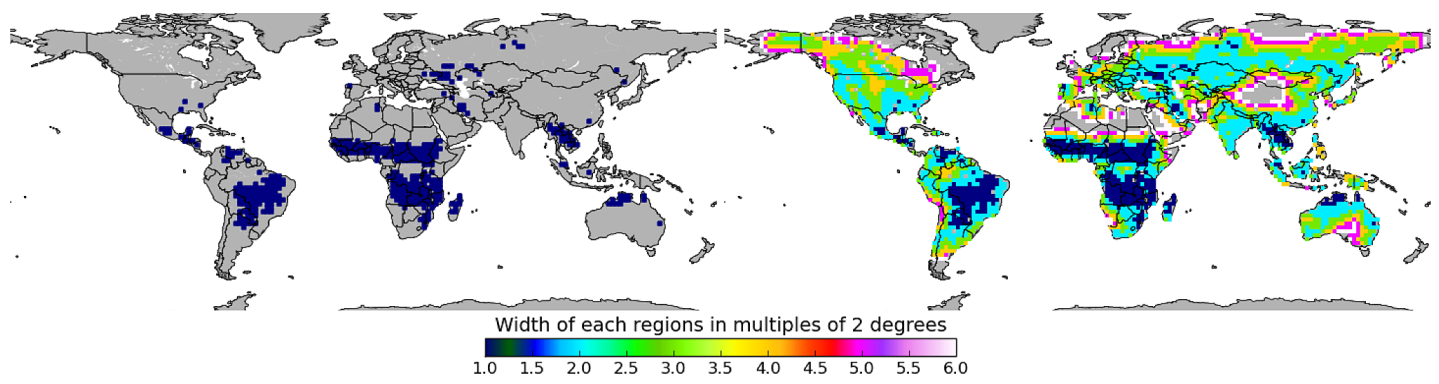

Figure 1. Width in multiples of $2^{\circ}$ of every region with more than 400 positive $0.5^{\circ}$ FRP grid cells from Terra and Aqua, in the period from 1 January 2003 to 31 December 2011. Fixed regions are on the left, and adaptive regionalization algorithm on the right.

significant impact on global FRP (see also Dahlkötter et al., 2014). To be able to take into account this geographical variability in fire activity patterns and the impact of different land covers, regression needs to be applied to regional subsets of the learning data set instead of a global one.

The verification data set extends from 1 January 2012 to 31 December of the same year.

\subsection{Two different regionalization strategies}

The sample size for every considered local data sets needs to be large enough for a regression algorithm to be applied safely. A minimal sample size of 400 positive gridded observations of FRP for both Aqua and Terra was chosen. Larger values for this threshold were tested, without much impact on the quality of the regression.

\subsubsection{Fixed regions}

The regression was applied to $2^{\circ} \times 2^{\circ}$ regions across the globe that contained more than 400 fires (as observed by both Aqua and Terra) in the learning data set. Tests with smaller regions showed that the statistical link between the data sets did not vary much from one region to another, while many more regions did not contain enough fires to be considered for regression.

\subsubsection{Adaptive regions}

In order not to exclude too many regions, an adaptive regionalization algorithm was also tested. If the sample does not meet the size criterion for a given $2^{\circ} \times 2^{\circ}$ tile, then all fires in a $4^{\circ} \times 4^{\circ}$ degrees regions centred on the original tile are considered. If there are still not enough fires in the $4^{\circ} \times 4^{\circ}$ region, then fires are considered in a $6^{\circ} \times 6^{\circ}$ region, and so on, up to a maximum area of $12^{\circ} \times 12^{\circ}$. Figure 1 shows the comparative areas that meet the sample size criterion for the two regionalization methods. It is clear from this figure that the "adaptive regionalization" algorithm allows us to apply regression to nearly the whole globe instead of a much smaller domain when using only $2^{\circ} \times 2^{\circ}$ domains. The regions where fires are very common, and especially the tropical forests and savannahs, are prominent in Fig. 1 when using fixed regions. A few regions that meet the sample size criterion lie in desert areas, such as at the border between Tunisia and Algeria or in southwestern Iran. These could be due to fires coming from gas extraction facilities that were not masked in GFAS. The comparative advantage of this regionalization strategy will be assessed in Sect. 3.

\subsection{Regression approaches}

\subsubsection{Linear regression}

The linear regression algorithm was applied to the two sets of regions described above and to the learning data set that extends from 2003 to 2011 . The algorithm consists of computing for every region, the linear regression coefficient $a$, and a coefficient $b$, such that

$\|\boldsymbol{Y}-(a \cdot \boldsymbol{X}+b)\|_{2}$

is minimal. $\boldsymbol{X}$ is the sample of $0.5^{\circ}$ daily FRP from Aqua or Terra contained in the considered region (i.e. the explanatory variable), and $\boldsymbol{Y}$ is the sample of $0.5^{\circ}$ FRP merged from both Aqua and Terra (i.e. the dependent variable). The correlation of the two variables will be evaluated on the learning data set using the square of the correlation coefficient $r^{2}$. The skill of the regression will be assessed on the verification data set by comparing the output of GFAS when assimilating corrected and uncorrected daily FRP from either Aqua or Terra. This comparison will be carried out by means of checking the bias and the root-mean-square error (RMSE) against GFAS used in the classical configuration, i.e. assimilating merged observations from both Terra and Aqua.

\subsubsection{Non-linear regression}

Three different kinds of non-linear regression formulae were tried: the polynomial $\sum_{i} a_{i} x^{i}$, the hyperbolic $\sum_{i} \frac{a_{i}}{x^{i}}$ and the exponential $a e^{b x}$ or $a x^{b}$, where $a, a_{i}$ and $b$ are parameters that are adjusted to find the best fit. Combinations of the three families were also tried, and it was shown that the approach that minimized the distance between the corrected daily FRP 
Table 1. RMSE and bias of mean global FRP in $\mathrm{mW} \mathrm{m}^{-2}$ for the year 2012 for Aqua- and Terra-GFAS with linear regression applied, as compared to Full-GFAS, fixed and adaptive regions.

\begin{tabular}{lccc}
\hline Satellite data assimilated & RMSE & Bias & Average FRP \\
\hline Aqua and GFAS & 0 & 0 & $2.238 \times 10^{-4}$ \\
Aqua (not corrected) & $1.059 \times 10^{-4}$ & $-8.7611 \times 10^{-5}$ & $3.112 \times 10^{-4}$ \\
Terra (not corrected) & $8.769 \times 10^{-5}$ & $7.541 \times 10^{-5}$ & $1.486 \times 10^{-4}$ \\
Aqua (fixed regions) & $4.349 \times 10^{-5}$ & $-2.952 \times 10^{-5}$ & $2.536 \times 10^{-4}$ \\
Terra (fixed regions) & $5.138 \times 10^{-5}$ & $3.304 \times 10^{-5}$ & $1.910 \times 10^{-4}$ \\
Aqua (adaptive regions) & $2.599 \times 10^{-5}$ & $-1.876 \times 10^{-6}$ & $2.260 \times 10^{-4}$ \\
Terra (adaptive regions) & $4.515 \times 10^{-5}$ & $2.503 \times 10^{-5}$ & $1.991 \times 10^{-4}$ \\
\hline
\end{tabular}

and the merged FRP was to combine a polynomial and the hyperbolic function:

$F(X)=a X^{4}+b X^{3}+c X^{2}+d X+\frac{e}{X}$,

where the five parameters $a, b, c, d$ and $e$ are determined for each region by minimizing the least-squares distance between $Y$ and $F(X)$ using the Levenberg-Marquardt algorithm (Marquardt, 1963).

\subsubsection{Combined regression}

It is also possible to combine the linear and non-linear approaches when correcting the verification data set. As the non-linear algorithm is less stable, for larger values of FRP the linear regression is preferred, while for smaller values non-linear regression is applied. The threshold between the two needs to be adaptive as outlying values are very timeand space-dependent. It was chosen to make this threshold depend on a given percentile of the whole daily FRP dataset. A sensitivity study was carried out with regard to what percentile gives the best results depending on which satellite observations are being corrected; its results are shown in Sect. 3 .

\subsubsection{Distance metrics}

In order to compare the results from linear, non-linear regressions and combined approaches, a common distance metric needs to be defined to be able to measure the efficiency of each algorithm. The classical regression coefficient is only applicable to linear regression algorithm. The approach chosen here is to compare, for each regional data set, the norms of the vector composed of the difference between the regression and the dependent variable, i.e.

$\|\boldsymbol{Y}-F(\boldsymbol{X})\|_{2}=\sqrt{\left(\sum_{i}\left(\boldsymbol{Y}_{i}-F\left(\boldsymbol{X}_{i}\right)\right)^{2}\right)}$,

where $\boldsymbol{Y}$ is the dependent variable vector, i.e. Full-GFAS here, composed of a sample of $\boldsymbol{Y}_{i}$ scalars; $\boldsymbol{X}$ is the explanatory variable vector, i.e. Aqua- or Terra-GFAS; and $F$ is the linear or non-linear regression algorithm applied to every component $X_{i}$ of this vector. This distance is not normalized by the size of the dependent variable vector; that means that its value also depends on the size of this vector. As we used this distance only to compare the various algorithms that were tried, this is not an issue here.

\section{Results with the verification data set}

In this section daily FRP from the verification data set are corrected by the different regressions shown above and then assimilated in Terra- and Aqua-GFAS. Table 1 shows the global daily FRP averaged over the verification data set, as computed by GFAS using observations from both Terra and Aqua, from Aqua only and from Terra only. The important bias of GFAS when running it with observations from only one satellite without any correction is very apparent in this table and gives an indication of the importance of the correction that needs to be made.

\subsection{Linear regression}

The linear regression was applied to regional data sets corresponding to fixed $2 \times 2$ regions with more than 400 fires, and to regional data sets provided by the adaptive regionalization algorithm.

\subsubsection{Results with the fixed regionalization}

Figure 2 shows the square of the correlation coefficient for the daily Aqua or Terra FRP against merged FRP. The square of the correlation coefficient is much higher for Aqua (values lie between 0.85 and 1) than for Terra (values generally lie between 0.5 and 0.8 ). This is not really surprising, considering that the overpass time of Aqua is generally closer to the fire activity peak. As such, Aqua FRP observations are usually larger than Terra's and correlation of Aqua daily FRP with the merged FRP is also larger.

For the same reason, the regression coefficient (not shown) is generally below 1 for Terra and above 1 for Aqua. However, the values are very different from one region to the other 


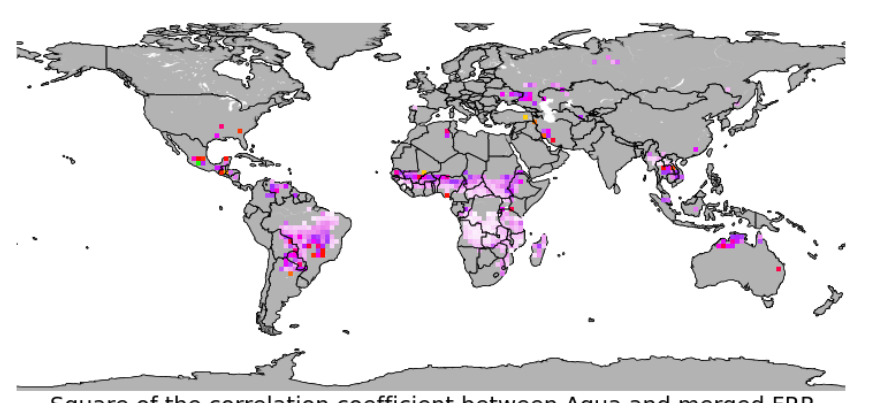

Square of the correlation coefficient between Aqua and merged FRP $\begin{array}{ccccccccc}0.32 & 0.40 & 0.48 & 0.56 & 0.64 & 0.72 & 0.80 & 0.88 & 0.96\end{array}$

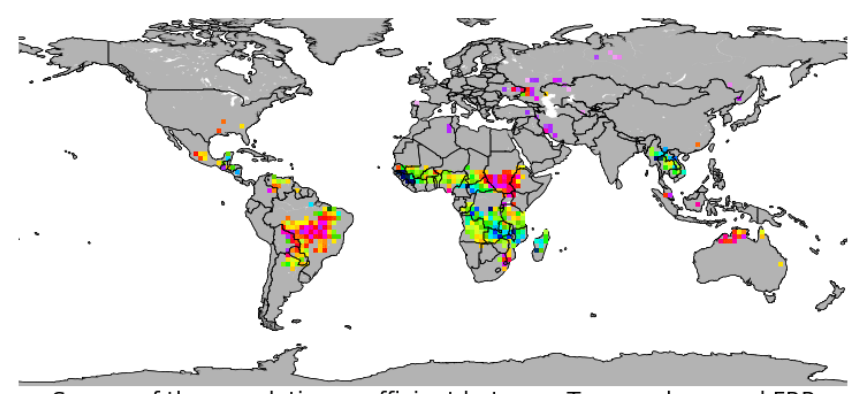

Square of the correlation coefficient between Terra and merged FRP $\begin{array}{ccccccccc}0.32 & 0.40 & 0.48 & 0.56 & 0.64 & 0.72 & 0.80 & 0.88 & 0.96\end{array}$

Figure 2. Square of the correlation coefficient between Aqua daily FRP (top), Terra daily FRP (bottom) and merged FRP. Fixed $2^{\circ} \times 2^{\circ}$ regions were used.

in both cases. The differences between the main groups of regions can be explained in terms of land cover, using the MODIS-based MCD12 land cover map version 5.1, shown in Fig. 3 for the year 2005 (Olofsson et al. (2012) and Stehman et al., 2012). Regions with relatively higher regression coefficients, such as northern Australia and South America, are predominantly savannah regions, while regions with woody savannah display lower regression coefficients (Africa, south of the Equator). Grasslands, like the ones that can be found in Africa north of the Equator, are in an intermediate position. An explanation for this different behaviour could lie in the different diurnal cycles associated with each of these land cover type, which could be a cause of the difference between fire intensity as observed by Terra in the morning and by Aqua at midday (e.g. Giglio, 2007; Roberts et al., 2009).

For easier reading, GFAS FRP obtained from assimilating only Aqua (Terra) FRP data from the verification data set will be called "Aqua-(Terra-)GFAS", while the reference GFAS FRP, obtained from assimilating FRP data from both satellites, will be called "Full-GFAS".

Table 1 shows the globally averaged RMSE and bias of the linear regression correction for Aqua- and Terra-GFAS as compared to Full-GFAS. The global average FRP is also indicated and can be compared to the global average FRP from GFAS when running with uncorrected daily FRP observations from Terra or Aqua. When the correction was not available, for example because the sample was too small, uncorrected values of daily FRP were used.

Comparison of the results from Table 1 shows that, for both Aqua- and Terra-GFAS, using daily FRP corrected by linear regression is rather efficient in bringing the average FRP closer to our reference. Using the corrected daily FRP reduced the bias by a factor of 3 for both Aqua- and TerraGFAS. The RMSE is quite high for both cases, with values that are 20 to $25 \%$ of the average FRP for Aqua- and TerraGFAS, respectively. This relatively high level of error can be partially explained by the bias, which represents more than half of the RMSE in both cases.

This first result is encouraging though not entirely satisfying because of the remaining bias and the relatively high level of RMSE.

\subsubsection{Results with the adaptive regionalization algorithm and comparison with fixed regions}

Figure 4 shows the square of the correlation coefficient of Aqua or Terra daily FRP with merged FRP, using the adaptive regionalization algorithm. In the regions where fires are common, the same features as with the fixed regions are displayed. In other regions, the impact of the land cover type is clearly shown: savannah and grassland regions in particular (United States, Australia outside the northern rim, Africa around the northern tropics) have very similar values. Boreal forests display regression coefficient (not shown) values close to 1 for both Aqua and Terra. This can be explained by the fact that fires in these regions do not occur as frequently as in the tropical forests but usually with a higher intensity. Intense fires tend to also burn during the nights and to limit the amplitude of the diurnal cycle. The correlation coefficients display larger values for Aqua daily FRP as compared to Terra daily FRP, for reasons already explained. The values are very close to 1 in most of the regions where fires were considered in a larger area than the original $2^{\circ} \times 2^{\circ}$ region. This means that enlarging the sample was not detrimental to how much the explanatory and the dependent variables are correlated in these regions.

Comparing the results with fixed and adaptive regions in Table 1 shows that the RMSE of the scaled Aqua-GFAS is reduced by nearly a factor of 2 when using the adaptive regionalization algorithm, and by more than $10 \%$ for Terra-GFAS. The bias is nearly entirely eliminated for Aqua-GFAS and reduced by a fourth for Terra-GFAS. These results show that including regions where fires are not as common as in the fixed regions helps a lot in improving the quality of the regression. The global average of FRP show that the regression nearly entirely eliminates the bias that was caused by using observations from only one satellite. 


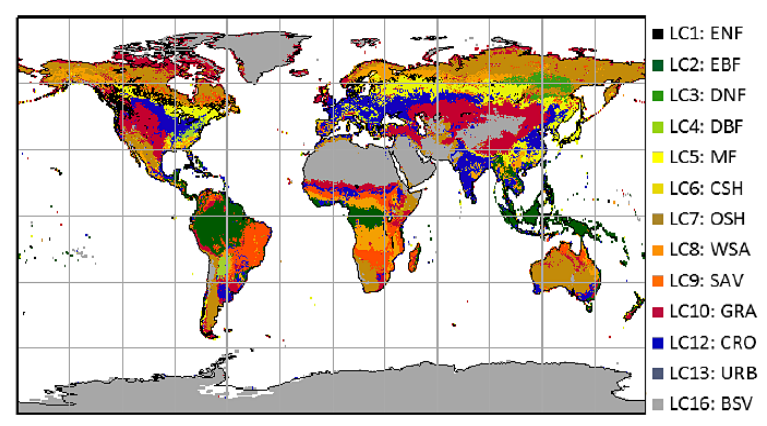

\begin{tabular}{|c|c|c|c|c|c|c|c|}
\hline \multirow{2}{*}{ LCCAT } & \multirow{2}{*}{ LC } & \multirow{2}{*}{ Description } & \multicolumn{5}{|c|}{ MCD12C1: 2005} \\
\hline & & & All & $\%$ & TRO & TEMP & BOR \\
\hline - ENF & 1 & Evergreen needleleaf forest & 2.8 & $2 \%$ & 0.1 & 0.7 & 2.1 \\
\hline - $\mathrm{EBF}$ & 2 & Evergreen broadleaf forest & 13.5 & $9 \%$ & 13.1 & 0.4 & 0.0 \\
\hline$=\mathrm{DNF}$ & 3 & Deciduous needleleaf forest & 1.5 & $1 \%$ & 0.0 & 0.0 & 1.5 \\
\hline$\triangle \mathrm{DBF}$ & 4 & Deciduous broadleaf forest & 1.9 & $1 \%$ & 0.8 & 1.0 & 0.1 \\
\hline$\square \mathrm{MF}$ & 5 & Mixed forest & 8.2 & $6 \%$ & 1.2 & 3.2 & 3.9 \\
\hline$\square \mathrm{CSH}$ & 6 & Closed shrublands & 0.3 & $0 \%$ & 0.2 & 0.1 & 0.1 \\
\hline$=\mathrm{OSH}$ & 7 & Open shrublands & 20.7 & $14 \%$ & 7.5 & 4.9 & 8.4 \\
\hline$=$ WSA & 8 & Woody savannas & 12.7 & $9 \%$ & 7.9 & 1.4 & 3.4 \\
\hline$=\mathrm{SAV}$ & 9 & Savannas & 11.4 & $8 \%$ & 9.7 & 0.3 & 1.4 \\
\hline$=$ GRA & 10 & Grasslands & 20.2 & $14 \%$ & 5.3 & 10.5 & 4.5 \\
\hline - CRO & 12 & Croplands & 16.5 & $11 \%$ & 6.4 & 7.5 & 2.7 \\
\hline$\because$ URB & 13 & Urban and built-up & 0.6 & $0 \%$ & 0.2 & 0.4 & 0.1 \\
\hline$=\mathrm{BSV}$ & 16 & Barren or sparsely vegetated & 34.2 & $24 \%$ & 13.0 & 5.9 & 15.3 \\
\hline Sum & & mio. $\mathrm{km}^{2}$ & 144.8 & $100 \%$ & 65.3 & 36.2 & 43.3 \\
\hline
\end{tabular}

Figure 3. Left: map of MCD12 (v5.1) land cover of the year 2005 (UMD classification) remapped to $0.1^{\circ}$ using largest area fraction approach. Right: area in millions of square kilometres of the UMD land cover classes.

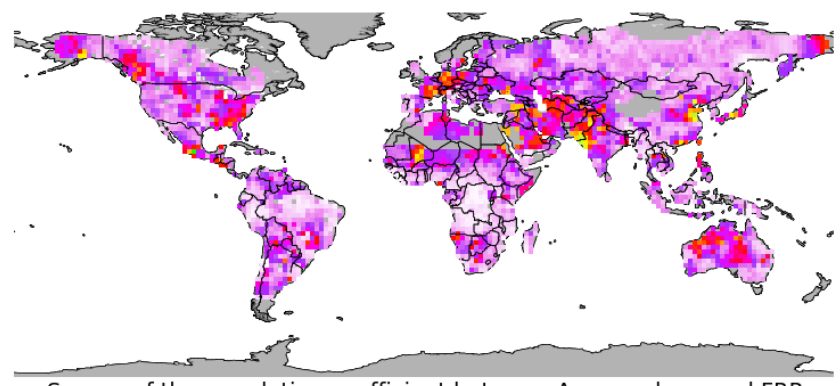

Square of the correlation coefficient between Aqua and merged FRP

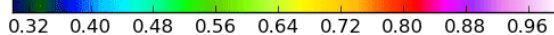

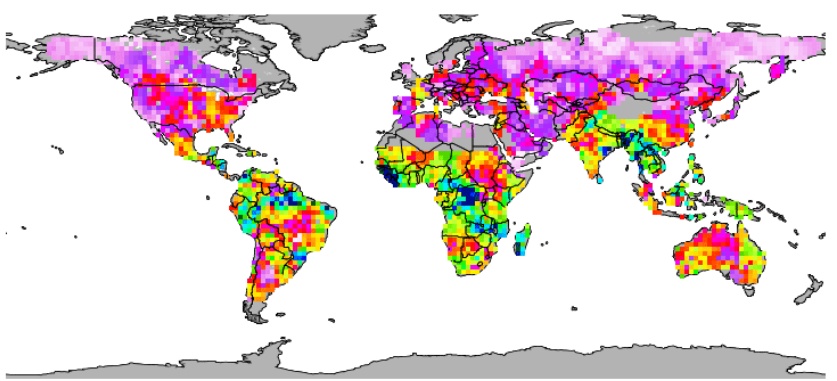

Square of the correlation coefficient between Terra and merged FRP

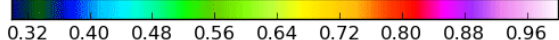

Figure 4. Square of the correlation coefficient between Aqua daily FRP (top), Terra daily FRP (bottom) and merged FRP with the adaptive regionalization algorithm.

\subsection{Non-linear regression and combined approach}

Non-linear regression was applied only to data sets provided by the adaptive regionalization algorithm, as it was shown that this algorithm improves significantly the quality of the regression. Using only the non-linear regression to correct observations brought a marked degradation when using these observations in GFAS. This degradation is caused by the fact that non-linear regression gave extreme results for a few fires with large FRP: this algorithm is much less stable as compared to linear regression. These values were non-physical above 100 and reached $5000 \mathrm{~W} \mathrm{~m}^{-2}$ over a $0.5^{\circ}$ grid cell.

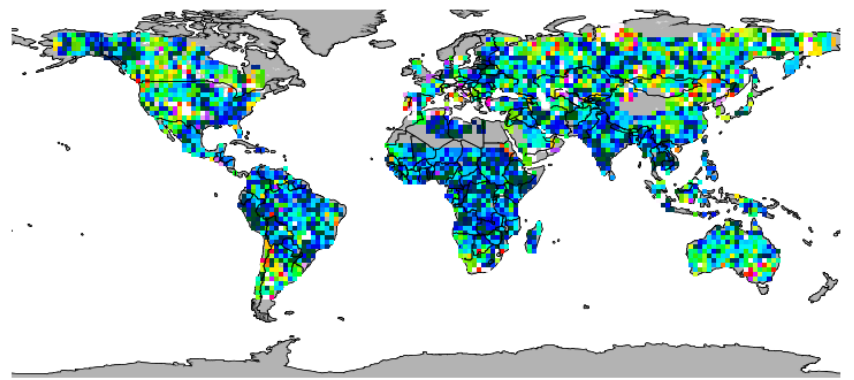

Aqua daily FRP. \% reduction in distance from merged FRP
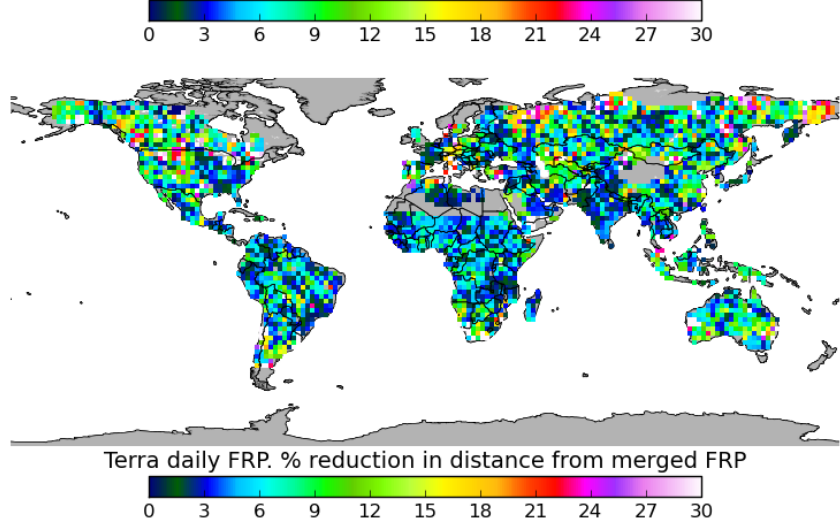

Figure 5. Reduction in per cent of the distance between daily FRP from Aqua (top), Terra (bottom) and merged FRP by the non-linear regression as compared to the linear regression.

Only a few grid cells were concerned, so the relative proportion of non-physical values being produced by the non-linear regression was negligible. However, as these values were so large, they significantly impacted the average FRP.

\subsubsection{Reasons for using the combined approach}

As we are dealing with data sets that are very varied, with weaker or stronger statistical links between them, a nonlinear regression will be more efficient in capturing the statistical link between Aqua and Terra daily FRP on the one hand and merged daily FRP on the other hand. This is shown by 

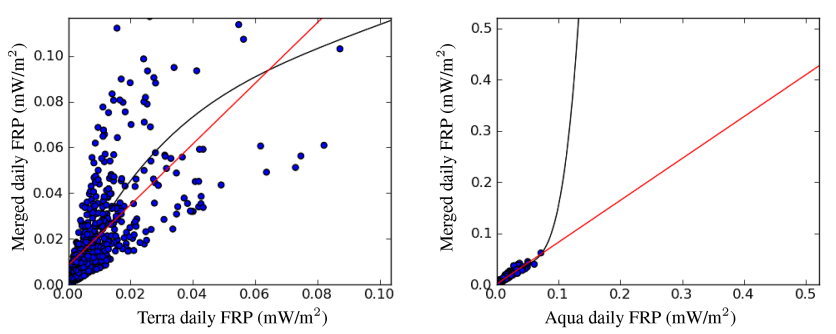

Figure 6. Scatter plot of Terra-(left) and Aqua(right) daily FRP together with merged FRP. The linear regression between the two data sets is shown as a red line while the best fit non-linear regression is shown in black. Regions considered are the square that extends from 24 to $26^{\circ}$ east and from 16 to $18^{\circ}$ south (left) and from 36 to $38^{\circ}$ east and 58 to $60^{\circ}$ north (right).

Figure 5, which presents the relative improvement brought by the non-linear regression relative to the linear regression as applied to the learning data set, in terms of distance to merged daily FRP. In many areas, the improvement is of the order of 10 to $20 \%$. The relative improvement brought by the non-linear approach as compared to the linear one is mostly evident in regions where fires are less common and as a consequence where the adaptive regionalization algorithm provides larger domains, as shown in Fig. 1. Also, the non-linear approach seems to have a larger impact for Terra as compared to Aqua as shown by Fig. 5 .

However, the non-linear formulae cannot be applied to the verification data set without removing the outlying data. The non-linear algorithm is generally more efficient in minimizing the error between the corrected FRP and the dependent variable. However, for very large daily FRP from Terra or GFAS, or if the difference between Aqua and Terra is too large because of difference cloud cover conditions, nonlinear regression can bring very large errors. In particular, applying the non-linear approach to daily FRP values that lies outside of the learning data set will give very poor results, while the linear approach is safer in this case. This is clearly shown by Fig. 6: if the non-linear approach is applied to large values, then the result will be extremely large (for the region considered in the right part of the figure) or even negative for the region considered on the left.

A way to exploit both the robustness of the linear algorithm and the added skill of the non-linear approach was found by designing and applying the combined algorithm that is explained in the Methods section. Several values for the daily threshold between the use of linear and non-linear approaches were tested on the verifying data set. The results of this sensitivity study are summed up in Table 2 for Aqua and Table 3 for Terra. The 100th percentile corresponds to the linear regression being applied only. These tables show a marked difference between Terra and Aqua. For Aqua, the RMSE decreases very fast with increasing percentiles, but quickly reaches a floor. Bias, however, decreases more regularly, reaches a minimum and then increases slightly again.
Table 2. RMSE and bias of mean global FRP in $\mathrm{mW} \mathrm{m}^{-2}$ for the year 2012 for Aqua-GFAS as a function of the percentile of gridded FRP above which linear regression is applied instead of non-linear regression.

\begin{tabular}{lccc}
\hline Percentile & RMSE & Bias & Average FRP \\
\hline 5 & $1.411 \times 10^{-4}$ & $-3.683 \times 10^{-5}$ & $2.609 \times 10^{-4}$ \\
10 & $7.098 \times 10^{-5}$ & $-1.574 \times 10^{-5}$ & $2.398 \times 10^{-4}$ \\
15 & $6.312 \times 10^{-5}$ & $-1.017 \times 10^{-5}$ & $2.343 \times 10^{-4}$ \\
20 & $2.969 \times 10^{-5}$ & $-5.898 \times 10^{-6}$ & $2.300 \times 10^{-4}$ \\
25 & $2.8385 \times 10^{-5}$ & $-4.105 \times 10^{-6}$ & $2.282 \times 10^{-4}$ \\
30 & $2.693 \times 10^{-5}$ & $-2.722 \times 10^{-6}$ & $2.268 \times 10^{-4}$ \\
35 & $2.635 \times 10^{-5}$ & $-2.076 \times 10^{-6}$ & $2.262 \times 10^{-4}$ \\
40 & $2.609 \times 10^{-5}$ & $-1.639 \times 10^{-6}$ & $2.257 \times 10^{-4}$ \\
45 & $2.610 \times 10^{-5}$ & $-1.425 \times 10^{-6}$ & $2.255 \times 10^{-4}$ \\
50 & $2.608 \times 10^{-5}$ & $-1.259 \times 10^{-6}$ & $2.254 \times 10^{-4}$ \\
60 & $2.605 \times 10^{-5}$ & $-1.180 \times 10^{-6}$ & $2.253 \times 10^{-4}$ \\
100 & $2.599 \times 10^{-5}$ & $-1.876 \times 10^{-6}$ & $2.260 \times 10^{-4}$ \\
\hline
\end{tabular}

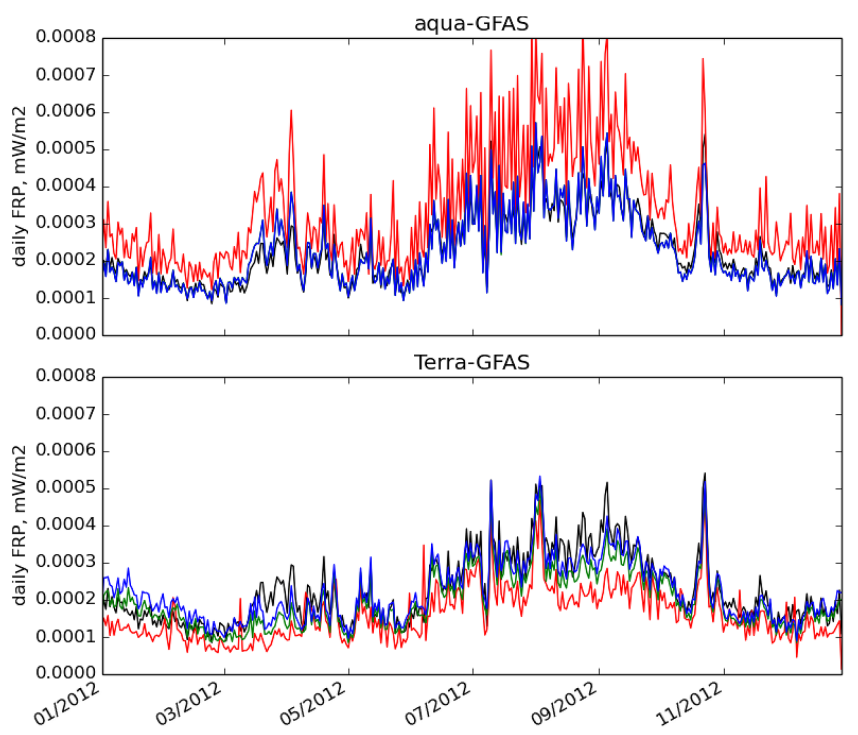

Figure 7. Daily global FRP from Aqua- and Terra-GFAS (in red) (Aqua, top; Terra, bottom) and from Full-GFAS (in black). The linear regression applied to Aqua- and Terra-GFAS is shown in green, while the mix of linear and non-linear approaches is displayed in blue. Data from 01/01/2012 to 31/12/2012.

Overall, the non-linear approach does not improve the scores much compared to the linear regression: the RMSE is the same and the bias is only slightly decreased. For Terra, both RMSE and bias decrease and then increase with the threshold percentiles. RMSE is much larger than for Aqua, and the non-linear approach is more efficient in reducing the bias. In the end, the percentiles that minimize the errors are 60 for Aqua and 45 for Terra; these are the values that will be used in the final correction algorithm. 


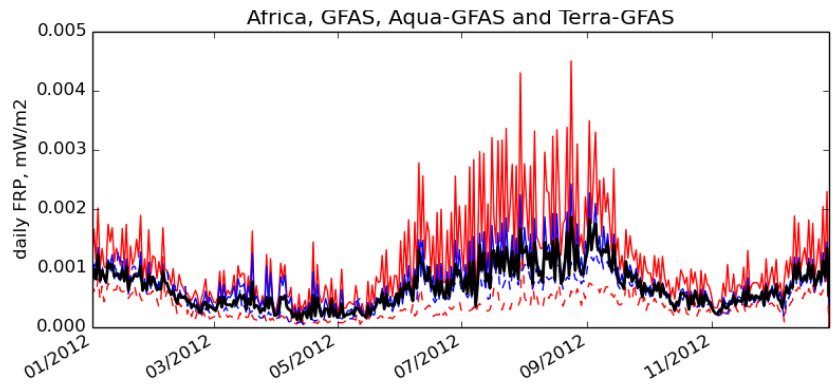

Table 3. RMSE and bias of mean global FRP in $\mathrm{mW} \mathrm{m}^{-2}$ for the year 2012 for Terra-GFAS as a function of the percentile of gridded FRP above which linear regression is applied instead of non-linear regression.

\begin{tabular}{lccc}
\hline Percentile & RMSE & Bias & Average FRP \\
\hline 5 & $1.114 \times 10^{-3}$ & $-2.981 \times 10^{-4}$ & $5.223 \times 10^{-4}$ \\
10 & $3.410 \times 10^{-4}$ & $-8.815 \times 10^{-5}$ & $3.122 \times 10^{-4}$ \\
15 & $2.075 \times 10^{-4}$ & $-3.897 \times 10^{-5}$ & $2.631 \times 10^{-4}$ \\
20 & $4.766 \times 10^{-5}$ & $-1.746 \times 10^{-5}$ & $2.416 \times 10^{-4}$ \\
25 & $4.183 \times 10^{-5}$ & $-1.239 \times 10^{-5}$ & $2.365 \times 10^{-4}$ \\
30 & $4.038 \times 10^{-5}$ & $-8.642 \times 10^{-6}$ & $2.327 \times 10^{-4}$ \\
35 & $3.916 \times 10^{-5}$ & $-4.957 \times 10^{-6}$ & $2.290 \times 10^{-4}$ \\
40 & $3.820 \times 10^{-5}$ & $-1.127 \times 10^{-6}$ & $2.252 \times 10^{-4}$ \\
45 & $3.758 \times 10^{-5}$ & $2.325 \times 10^{-6}$ & $2.218 \times 10^{-4}$ \\
50 & $3.725 \times 10^{-5}$ & $5.773 \times 10^{-6}$ & $2.183 \times 10^{-4}$ \\
60 & $3.828 \times 10^{-5}$ & $1.122 \times 10^{-5}$ & $2.129 \times 10^{-4}$ \\
100 & $4.515 \times 10^{-5}$ & $2.503 \times 10^{-5}$ & $1.991 \times 10^{-4}$ \\
\hline
\end{tabular}

as how both the linear and combined algorithms are successful overall in scaling Aqua-GFAS towards Full-GFAS, except for a few large fire events such as in March and April 2012 and also at the end of October 2012. The differences between the linear and combined approaches are very small. For Terra-GFAS, the regression is overall less successful, in particular up to 1 May 2012. For Aqua, the daily FRP as provided by GFAS using observations corrected by the combined algorithm is 5-30\% larger as compared to the values obtained with the linear regression. For Terra, the difference is generally negligible as a global average. As also shown in Table 3, applying linear regression has a greater impact on Terra than on Aqua.

The apparent difference between the small improvement brought by the combined regression when applied to the verifying data set and the larger reduction of the distance resulting from the same method when applied to the learning data set (see Fig. 5) can be explained by the fact that the regions where the combined algorithm reduces this distance the most are the regions where fires are less common. The tropical forests and savannahs, which contribute generally the most to the global FRP, do not show much improvement in the combined method as compared to linear regression in Fig. 5. This shows that non-linear regression has the most impact on fires in regions that generally contribute much to global FRP, and therefore this improvement is not very visible when considering daily global FRP, even though it is locally important.

Figure 8 shows daily FRP from Aqua-, Terra- and FullGFAS, averaged over Africa, Indonesia, and South and North America. GFAS output using observations not corrected and corrected with the combined algorithm is shown. This figure clearly shows the varying ratio Aqua over Terra from region to region: it is important in Africa, where Aqua values can be up to 8 times larger than Terra value, and rather small in 

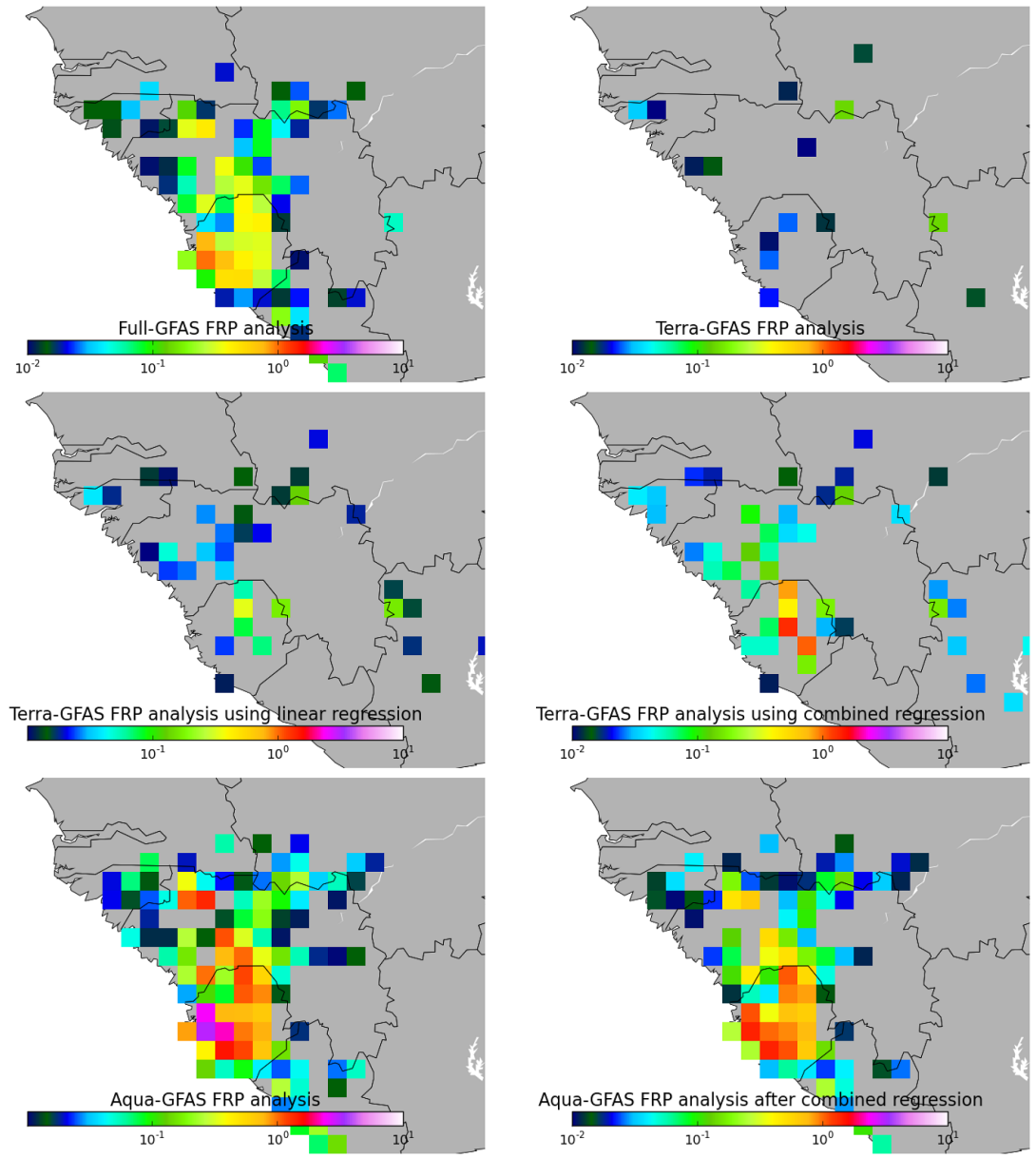

Figure 9. Daily FRP in $\mathrm{mW} \mathrm{m}^{2}$ for West Africa on 03/04/2012, given by Full-GFAS (top left), Terra-GFAS (top right), Terra-GFAS using linear regression (middle left) and non-linear regression (middle right), as well as Aqua-GFAS (bottom left) and Aqua-GFAS using non-linear regression (bottom right).

North America, where Aqua values are usually 5-15\% larger than Terra.

A spurious oscillation of daily FRP as estimated by Aqua observations, with a 2-day frequency, is very prominent in Africa. This is caused by the fact that the detection threshold of the MODIS sensor varies across the swath. It increases with viewing angle, towards the swath edges (e.g. Freeborn et al., 2011); this leads to lower FRP estimates in GFAS for grid cells that are observed nearer the MODIS swath edges as smaller fires are not taken into account. As for both Aqua and Terra, there are fewer overpasses around the Equator; this results in an underestimation of FRP every 2 days. This shows more clearly for Aqua, because it captures better the maximum intensity of fires thanks to its overpass time. This underestimation in the FRP analysis over Africa is compensated for by the fact that the conversion factors to convert FRP into dry matter burnt were computed using monthly average FRP from GFAS and monthly average dry matter combustion rates of GFED (Andela et al., 2013). This issue will be addressed in the next version of GFAS, which will include a correction of FRP observations to account for the detection threshold of MODIS as a function of the viewing angle. The algorithm of this correction is shown in detail in Kaiser et al. (2013).

Figure 8 also shows that the correction algorithm is very efficient in bringing both Terra- and Aqua-GFAS towards Full-GFAS for the four considered regions. For South America, the relative improvement brought by the correction appears more important for Aqua-GFAS than for Terra-GFAS.

\subsubsection{Results of the combined algorithm to linear regression in two case studies}

To focus to a local scale, Fig. 9 shows the impact of both methods on a particular fire event in West Africa on 3 April 2012. The daily FRP analysis from GFAS using the original Terra data set shows values that are largely inferior to merged FRP, whereas they are superior for the original Aqua data set. The observed area (not shown) are comparable for both satellites on that day, which means that different cloudi- 

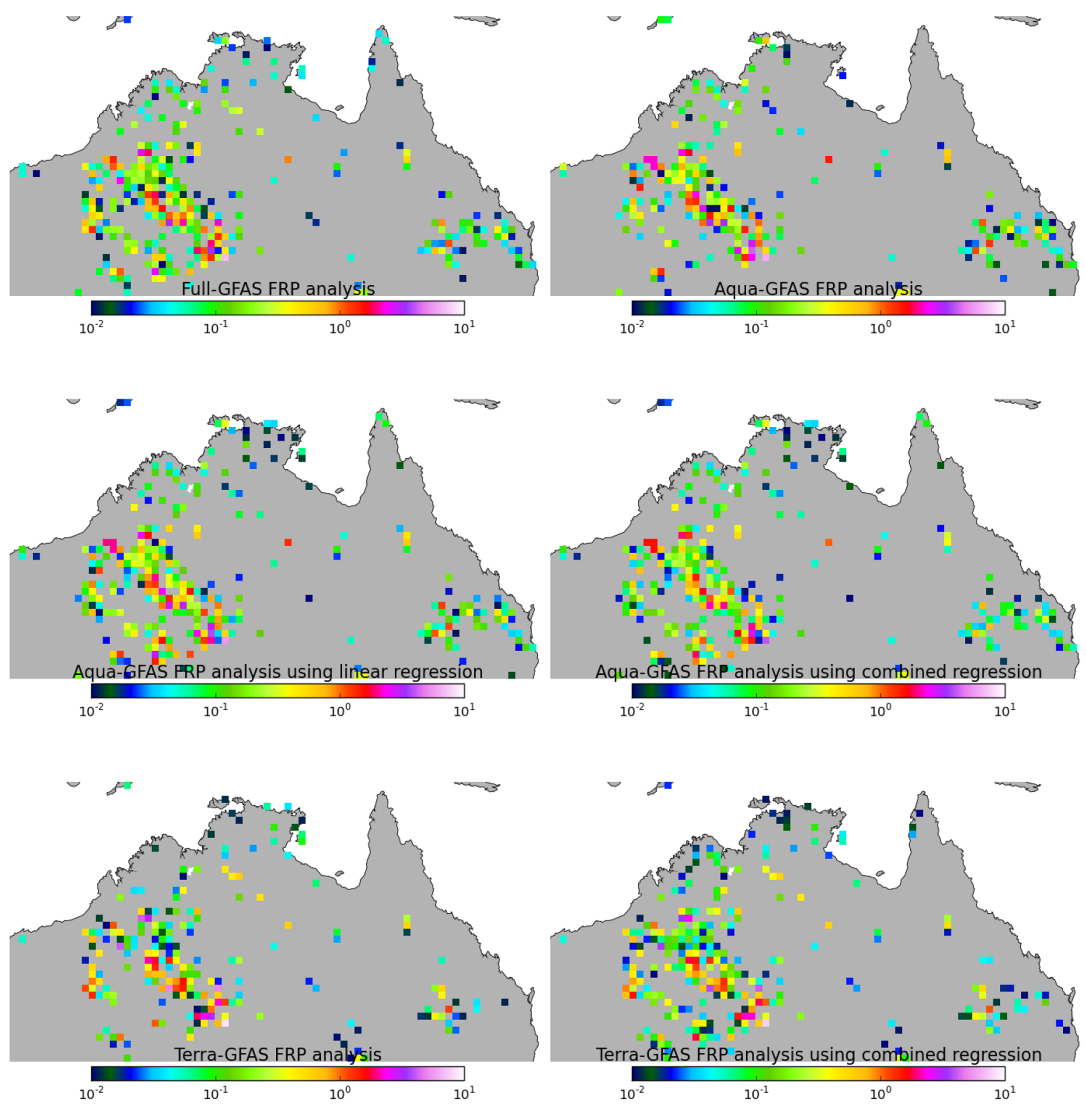

Figure 10. Daily FRP in $\mathrm{mW} \mathrm{m}^{-2}$ for Australia on 23/10/2012, given by Full-GFAS (top left), Aqua-GFAS (top right), Aqua-GFAS using linear regression (middle left) and non-linear regression (middle right), as well as Terra-GFAS (bottom left) and Terra-GFAS using non-linear regression (bottom right).

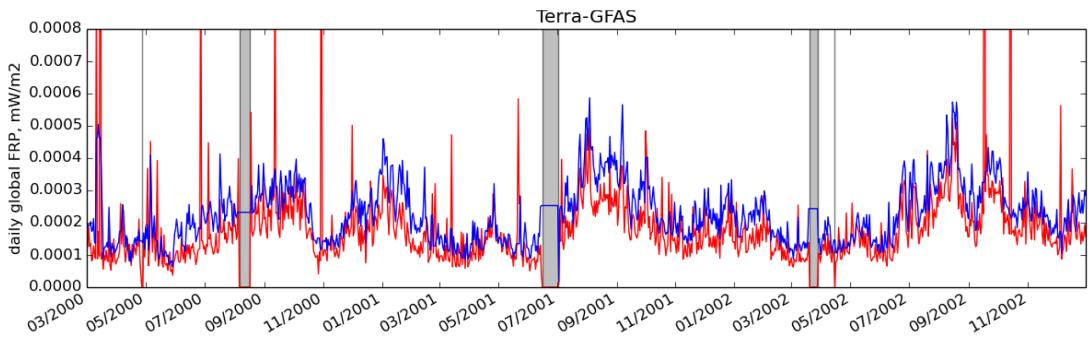

Figure 11. Daily global FRP from Terra-GFAS from 24/02/2000 to 31/12/2002 using non-corrected observations (red) and corrected observations (blue). The grey areas indicate that the MODIS/Terra observations were not available and that persistence was used instead in Terra-GFAS.

ness between the Terra and Aqua overpass times is not the cause of this very important difference. This fire event contributed significantly to global FRP on that day, and as Fig. 7 shows, the correction of Terra values was not very successful on that particular day on a global scale. The causes of this relative lack of success for Terra are clear when considering the difference between the uncorrected Terra-GFAS and Aqua-GFAS. Many fires that were detected by Aqua were not detected by Terra; as a consequence, the correction algorithm, even though it significantly reduced the difference between Terra-GFAS and Full-GFAS, still showed important errors. The correction algorithm was successful in producing a maximal FRP for Terra-GFAS that was of the order of magnitude of the one observed in Full-GFAS. This was accomplished by the non-linear part of the correction algorithm, as shown by the differences between the linear correction and the combined approach results in Fig. 7.

For this particular example, the combined approach scales FRP from Terra-GFAS closer to Full-GFAS as compared to linear regression. The different behaviour of both regression 
Table 4. RMSE and bias of mean global FRP in $\mathrm{mW} \mathrm{m}^{-2}$ for the year 2012 for Full-GFAS (reference), uncorrected Aqua- and Terra-GFAS, and corrected Aqua- and Terra-GFAS, against Full-GFAS FRP

\begin{tabular}{lccc}
\hline Satellite data assimilated & RMSE & Bias & Average FRP \\
\hline Aqua and GFAS & 0 & 0 & $2.238 \times 10^{-4}$ \\
Aqua (not corrected) & $1.059 \times 10^{-4}$ & $-8.7611 \times 10^{-5}$ & $3.112 \times 10^{-4}$ \\
Terra (not corrected) & $8.769 \times 10^{-5}$ & $7.541 \times 10^{-5}$ & $1.486 \times 10^{-4}$ \\
Aqua (corrected) & $2.605 \times 10^{-5}$ & $-1.180 \times 10^{-6}$ & $2.253 \times 10^{-4}$ \\
Terra (corrected) & $3.758 \times 10^{-5}$ & $2.325 \times 10^{-6}$ & $2.218 \times 10^{-4}$ \\
\hline
\end{tabular}

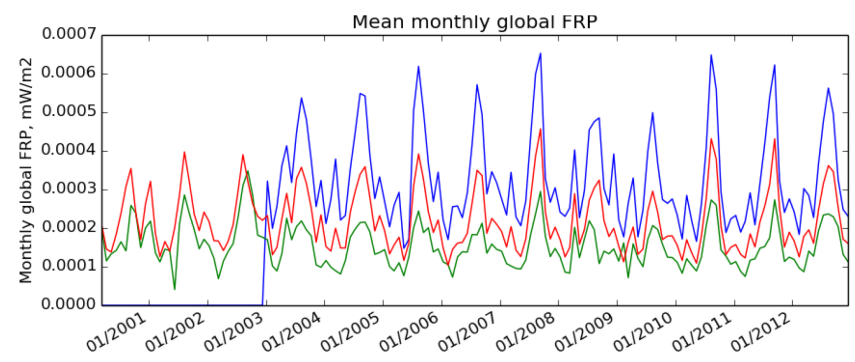

Figure 12. Monthly global FRP from Terra (green), Aqua (blue) and GFAS (red). Before 01/01/2003, GFAS uses Terra observations corrected with a combination of linear and non-linear regression; after 01/01/2003, GFAS uses observations from Aqua and Terra.

methods from one region to another is clear when considering that the maximum FRP does not occur in the same grid cell once either regression method is applied.

This figure shows that, at a local scale, errors are reduced by the regression but can still remain important. It also shows that the differences from the linear and combined regressions are larger when considered at a local scale.

Figure 10 shows how both regression algorithms perform at a local scale on 23 October 2012 for fires in Australia that were an important contribution to the peak of global FRP that was observed that day, as shown in Fig. 7. The differences between the FRP analysis from Full-GFAS, Terra-GFAS and Aqua-GFAS using non-corrected data are visible but much less important than in the other case. As a result, the regression is much more efficient in producing daily FRP that bring Terra-GFAS and Aqua-GFAS FRP analysis closer to FullGFAS. The non-linear approach does not have any visible impact in that case.

\section{Extension of the GFAS emissions database}

The combined linear and non-linear approach was applied to Terra-GFAS for the period extending from 24 February 2000 to 31 December 2002. Static correction (volcanoes, gas flares) and quality control were carried out as described in Kaiser et al. (2012): all observations with a daily FRP value above $20^{\circ} \mathrm{W}$ (average for a $0.5^{\circ}$ grid cell) per square metre were not taken into account.
Figure 11 shows Terra-GFAS using uncorrected daily FRP from Terra, as well as values corrected with linear regression and non-linear regression. The correction brings greater GFAS FRP analysis: the mean daily global FRP for the 24 February 2000 to 31 December 2002 period is $1.79 \times 10^{-4} \mathrm{~mW} \mathrm{~m}^{-2}$ when using uncorrected Terra daily FRP, and $2.31 \times 10^{-4} \mathrm{~mW} \mathrm{~m}^{-2}$ when using corrected Terra daily FRP. These averages are comparable to the values for the year 2012 when using merged daily FRP: $1.486 \times 10^{-4}$ and $2.238 \times 10^{-4} \mathrm{~mW} \mathrm{~m}^{-2}$, respectively.

Figure 12 shows monthly global FRP from Aqua, Terra and GFASv1.0, including the extension of GFAS for the period extending from 24 February 2000 to 31 December 2002. While the unavailability of any independent verifying satellite observations makes it impossible to quantitatively assess the accuracy of the corrected FRP, the values for the years 2000 to 2002 show a good agreement with the values afterwards.

The observation products (MOD14) from Terra contain no fire detections for a few periods, especially from 6 to $17 \mathrm{Au}-$ gust 2000, from 16 June to 2 July 2001 and from 21 to 29 March 2002. This kind of data fault cannot be detected by the implemented quality control. Therefore, we assume persistence of the fire distribution for these specific dates.

FRP and biomass burning emissions for the period of 1 March 2000 to 31 December 2002 have been added to the GFASv1.0 database, which now encompasses the years 2000-2014.

\section{Summary}

Several configurations for the correction of Aqua and Terra daily FRP were tried. The adaptive regionalization improves the result of GFAS as compared to the fixed regionalization for both satellites, more so for Aqua as compared to Terra (see Table 1). The combination of non-linear and linear approaches is more efficient for Terra than for Aqua (see Tables 2 and 3 ).

Table 4 shows the final scores for Aqua- and Terra-GFAS, corrected with the adaptive regionalization algorithm and the combined linear-non-linear approach. The correction improves the RMSE by more than $75 \%$ for Aqua-GFAS and 
$55 \%$ for Terra-GFAS. The bias is also improved by more than $95 \%$ for both Aqua and Terra. While the correction is very efficient at reducing the bias at a global scale, errors can be large when considered at a local scale, as on 3 April 2012 in West Africa (see Fig. 9).

\section{Conclusions}

This paper showed that a combination of linear and nonlinear regression manages to effectively remove the bias of the output of GFAS when using observations from only Aqua or Terra. These results are qualitatively similar to the results obtained by Ellicott et al. (2009) with a different system. The regression is overall more efficient for Aqua than for Terra, and was designed to address the difference between Aqua and Terra caused by the diurnal cycle of fires. This will ensure the coherence of the output of GFAS at a global scale, should one of these satellites fail. As such, this work consolidated the whole MACC-II system. The GFAS FRP and biomass burning emissions database was successfully extended to the period from 24 February 2000 to 1 January 2003.

As the fire typology varies a lot from one region to the other, an adaptive regionalization algorithm was successfully implemented to design samples that were statistically significant. This allowed us to run the regression in nearly every region of the globe where fires occurred in the past 9 years. For regions where fires were too scarce for the regression algorithms to be run safely, which represent a very small fraction of all fires, the correction shown here cannot be applied. The approach that was applied here to MODIS observations on Aqua and Terra is also applicable to FRP observations from other sources, e.g. SEVIRI, VIIRS and SLSTR, acting as a bias correction. That would open the possibility of assimilating more FRP observations in GFAS.

This work also documented the differences between Aqua and Terra FRP observations. These differences are important at a global scale, and even more so at a local scale, as shown by the 3 April 2012 situation in West Africa.

\section{The Supplement related to this article is available online at doi:10.5194/acp-14-13377-2014-supplement.}

Acknowledgements. We thank NASA for providing the MODIS data. We also wish to thank the two anonymous reviewers for their insightful remarks that led to improvements in this paper. This research was supported by the EU Seventh Research Framework Programme (MACC-II project, contract number 283576)

Edited by: B. Vogel

\section{References}

Andela, N., Kaiser, J. W., Heil, A., Van Leeuwen, T. T., van der Werf, G. R., Wooster, M. J., Remy, S., and Schultz, M. G.: Assessment of the Global Fire Assimilation System (GFASv1), available at: https://gmes-atmosphere.eu/documents/ maccii/deliverables/fir, 2013.

Andreae, M. O., and Merlet, P.: Emission of trace gases and aerosols from biomass burning, Global Biogeochem. Cy., 15, 955-966, 2001.

Bowman, D. M. J. S., Balch, J. K., Artaxo, P., Bond, W. J., Carlson, J. M., Cochrane, M. A., D’Antonio, C. M., DeFries, R. S., Doyle, J. C., Harrison, S. P., Johnston, F. H., Keeley, J. E., Krawchuk, M. A., Kull, C. A., Marston, J. B., Moritz, M. A., Prentice, I. C., Roos, C. I., Scott, A. C., Swetnam, T. W., van der Werf, G. R., and Pyne, S. J.: Fire in the Earth System, Science, 324, 481-484, 2009.

Bond, T. C., Doherty, S. J., Fahey, D. W., Forster, P. M., Berntsen, T. K., Boucher, O., DeAngelo, B. J., Flanner, M. G., Ghan, S. J., Kärcher, B., Koch, D., and Kinne, S., Kondo, Y., Lohmann, U., Quinn, P. K., Sarofim, M. C., Schultz, M., Schulz, M., Venkataraman, C., Zhang, H., Zhang, S., Bellouin, N., Guttikunda, S., Hopke, P. K., Jacobson, M. Z., Kaiser, J. W., Klimont, Z., Schwarz, J. P., Shindell, D., Storelvmo, T., Warren, S. G., and Zender, C. S.: Bounding the role of black carbon in the climate system: A scientific assessment, J. Geophys. Res., 118, 1-173, 2013.

Dahlkötter, F., Gysel, M., Sauer, D., Minikin, A., Baumann, R., Seifert, P., Ansmann, A., Fromm, M., Voigt, C., and Weinzierl, B.: The Pagami Creek smoke plume after long-range transport to the upper troposphere over Europe - aerosol properties and black carbon mixing state, Atmos. Chem. Phys., 14, 6111-6137, doi:10.5194/acp-14-6111-2014, 2014.

Damenov, A. and da Silva, A.: The Quick Fire Emissions Dataset (QFED) - Documentation of versions 2.1, 2.2 and 2.4, NASA Technical Report Series on Global Modeling and Data Assimilations, 32, 2013.

Diehl, T., Heil, A., Chin, M., Pan, X., Streets, D., Schultz, M., and Kinne S.: Anthropogenic, biomass burning, and volcanic emissions of black carbon, organic carbon and $\mathrm{SO}_{2}$ from 1980 to 2010 for hindcast model experiment, Atmos. Chem. Phys. Discuss., 12, 24895-24954, 2012, http://www.atmos-chem-phys-discuss.net/12/24895/2012/.

Ellicott, E., E. Vermote, L. Giglio, and G. Roberts, Estimating biomass consumed from fire using MODIS FRE, Geophys. Res. Lett., 36, L13401, doi:10.1029/2009GL038581, 2009.

Freeborn, P. H. and Wooster, M. J.: Addressing the spatiotemporal sampling design of MODIS to provide estimates of the fire radiative energy emitted from Africa, Remote Sens. Environ., 115, 2, 475-489, 2011.

Freitas, S. R., Longo, K. M., Silva Dias, M. A. F., Silva Dias, P. L., Chatfield, R., Prins, E., Artaxo, P., Grell, G. A., and Recuero, F. S.: Monitoring the transport of biomass burning emissions in South America, Environ. Fluid Mech., 5, 135-167, 2005.

MODIS Collection 4 Active Fire Product User's Guide Version 2.3, Science Systems and Applications, Inc, 2005.

Giglio, L.: Characterization of the tropical diurnal fire cycle using VIRS and MODIS observations, Remote Sens. Environ., 108, 407-421, 2007. 
Giglio, L., Descloitres, J., Justice, C. O., and Kaufman, Y.: An enhanced contextual fire detection algorithm for MODIS, Remote Sens. Environ., 87, 273-282, 2003.

Giglio, L., Csiszar, I., Justice, C. O.: Global distribution and seasonality of active fires as observed with the Terra and Aqua MODIS sensors, J. Geophys. Res.-Biogeosci., 111, G02016, doi:10.1029/2005JG000142, 2006.

Heil, A., Kaiser, J. W., van der Werf, G. R., Wooster, M. J., Schultz, M. G., and Dernier van der Gon, H.: Assessment of the RealTime Fire Emissions (GFASv0) by MACC, Tech. Memo. 628, ECMWF, Reading, UK, 2010.

Hollingsworth, A., Engelen, R. J., Textor, C., Benedetti, A., Boucher, O., Chevallier, F., Dethof, A., Elbern, H., Eskes, H., Flemming, J., Granier, C., Kaiser, J. W., Morcrette, J.-J., Rayner, P., Peuch, V.-H., Rouil, L., Schultz, M. G., and Simmons, A. J.: Toward a Monitoring and Forecasting System For Atmospheric Composition: The GEMS Project, B. Am. Meteor. Soc., 89, 1147-1164, 2008.

Inness, A., Baier, F., Benedetti, A., Bouarar, I., Chabrillat, S., Clark, H., Clerbaux, C., Coheur, P., Engelen, R. J., Errera, Q., Flemming, J., George, M., Granier, C., Hadji-Lazaro, J., Huijnen, V., Hurtmans, D., Jones, L., Kaiser, J. W., Kapsomenakis, J., Lefever, K., Leitão, J., Razinger, M., Richter, A., Schultz, M. G., Simmons, A. J., Suttie, M., Stein, O., Thépaut, J.-N., Thouret, V., Vrekoussis, M., Zerefos, C., and the MACC team: The MACC reanalysis: an $8 \mathrm{yr}$ data set of atmospheric composition, Atmos. Chem. Phys., 13, 4073-4109, doi:10.5194/acp-13-4073-2013, 2013.

Justice, C. O., Giglio, L., Korontzi, S., Owens, J., Morisette, J. T., Roy, D., Descloitres, J., Alleaume, S., Petitcolin, F., and Kaufman, Y.: The MODIS fire products, RSE, 83, 244-262, 2002.

Kaiser, J. W., Andela, N., Atherton, J., de Jong, M., Heil, A., Paugam, R., Remy, S., Schultz, M. G., van der Werf, G. R., van Leeuwen, T. T., and Wooster, M. J.: Recommended Fire Emission Service Enhancements, available at https: //gmes-atmosphere.eu/documents/maccii/deliverables/fir, 2013.

Kaiser, J. W., Heil, A., Andreae, M. O., Benedetti, A., Chubarova, N., Jones, L., Morcrette, J.-J., Razinger, M., Schultz, M. G., Suttie, M., and van der Werf, G. R.: Biomass burning emissions estimated with a global fire assimilation system based on observed fire radiative power, Biogeosciences, 9, 527-554, doi:10.5194/bg-9-527-2012, 2012.

Kaiser, J. W., Suttie, M., Flemming, J., Morcrette, J.-J., Boucher, O., and Schultz, M. G.: Global Real-time Fire Emission Estimates Based on Space-borne Fire Radiative Power Observations, AIP Conf. Proc., 1100, 645-648, 2009.

Marquadt, D.: An Algorithm for Least-Squares Estimation of Nonlinear Parameters, J. Soc. Indust. Appl. Math., 11, 432-441, 1963.
Olofsson, P., Stehman, S. V., Woodcock, C. E., Friedl, M. A. Sulla-Menashe, D., Sibley, A. M., Newell, J. D., and Herold, M.: A global land cover validation data set, I: Fundamental Design principles, Int. J. Remote Sens., 33, 5768-5788, doi:10.1080/01431161.2012.674230, 2012.

Reid, J. S., Hyer, E. J., Prins, E. M., Westphal, D. L., Zhang, J., Wang, J., Christopher, S. A., Curtis, C. A., Schmidt, C. C., Eleuterio, D. P., Richardson, K. A., and Hoffman, J. P.: Global Monitoring and Forecasting of Biomass-Burning Smoke: Description of and Lessons from the Fire Locating and Modeling of Burning Emissions (FLAMBE) Program, IEEE J. Select. Topics Appl. Earth Obs. Remote Sens., 2, 144-162, 2009.

Roberts, G., Wooster, M. J., and Lagoudakis, E.: Annual and diurnal african biomass burning temporal dynamics, Biogeosciences, 6 , 849-866, doi:10.5194/bg-6-849-2009, 2009.

Sofiev, M., Vankevich, R., Lotjonen, M., Prank, M., Petukhov, V., Ermakova, T., Koskinen, J., and Kukkonen, J.: An operational system for the assimilation of the satellite information on wildland fires for the needs of air quality modelling and forecasting, Atmos. Chem. Phys., 9, 6833-6847, doi:10.5194/acp-9-68332009, 2009.

Stehman, S. V., Olofsson, P., Woodcock, C. E., Herold, M., and Friedl, M. A.: A global land cover validation data set, II: Augmenting a stratified sampling design to estimate accuracy by region and land-cover class, Int. J. Remote Sens., 33, 6975-6993, 2012.

van der Werf, G. R., Randerson, J. T., Giglio, L., Collatz, G. J., Kasibhatla, P. S., and Arellano Jr., A. F.: Interannual variability in global biomass burning emissions from 1997 to 2004, Atmos. Chem. Phys., 6, 3423-3441, doi:10.5194/acp-6-3423-2006, 2006.

van der Werf, G. R., Randerson, J. T., Giglio, L., Collatz, G. J., Mu, M., Kasibhatla, P. S., Morton, D. C., DeFries, R. S., Jin, Y., and van Leeuwen, T. T.: Global fire emissions and the contribution of deforestation, savanna, forest, agricultural, and peat fires (19972009), Atmos. Chem. Phys., 10, 11707-11735, doi:10.5194/acp10-11707-2010, 2010.

Wiedinmyer, C., Akagi, S. K., Yokelson, R. J., Emmons, L. K., AlSaadi, J. A., Orlando, J. J., and Soja, A. J.: The Fire INventory from NCAR (FINN): a high resolution global model to estimate the emissions from open burning, Geosci. Model Dev., 4, 625641, doi:10.5194/gmd-4-625-2011, 2011.

Wooster, M. J., Zhukov, B., and Oertel, D.: Fire radiative energy for quantitative study of biomassburning from the BIRD experimental satellite and comparison to MODIS fire products, Remote Sens. Environ., 86, 83-107, 2003. 